\title{
Low temperature sintering and Dielectric properties of
}

\section{$\left(\mathrm{Ba}_{0.85} \mathrm{Ca}_{0.15}\right)\left(\mathrm{Ti}_{0.9} \mathrm{Zr}_{0.1}\right) \mathrm{O}_{3^{-}} \mathrm{xCu^{2+ }}$ ceramics obtained by the sol-gel}

\section{technique}

Zhongming Wang ${ }^{\mathrm{a}}$, Xiaofang Chen ${ }^{\mathrm{a}}$, Xiaolian Chao ${ }^{\mathrm{a} \dagger}$, Juanjuan Wang ${ }^{\mathrm{b}}$, Pengfei Liang $^{\mathrm{a}}$, Zupei Yang ${ }^{\mathrm{a} \dagger}$

${ }^{\mathrm{a}}$ Key Laboratory for Macromolecular Science of Shaanxi Province School of Materials Science and Engineering, Shaanxi Normal University, Xi'an, 710062, Shaanxi, China

${ }^{\mathrm{b}}$ School of Materials Science and Engineering, Xi'an University of Technology, Xi'an, 710048, Shaanxi, China

Corresponding author:

Key Laboratory for Macromolecular Science of Shaanxi Province

School of Materials Science and Engineering

Shaanxi Normal University, Xi'an, 710062, Shaanxi, P. R. China

Tel: +86-29-8153-0718; Fax: +86-29-8153-0702

E-mail address: chaoxl@ snnu.edu.cn yangzp@snnu.edu.cn 


\begin{abstract}
Lead-free $\mathrm{Cu}^{2+}$-modified $\left(\mathrm{Ba}_{0.85} \mathrm{Ca}_{0.15}\right)\left(\mathrm{Ti}_{0.9} \mathrm{Zr}_{0.1}\right) \mathrm{O}_{3}\left(\mathrm{BCZT}-x \mathrm{Cu}^{2+}\right)$ piezoelectric ceramics was synthesized by sol-gel method. The effects of $\mathrm{Cu}^{2+}$ additions on sintering characteristics, the phase structure, microstructure, electrical properties and complex impedance characteristic were investigated systematically. The XRD patterns exhibited a pure perovskite structure without impurity phase in all samples. SEM micrographs, temperature dependence of dielectric constant and polarizationelectric field $(P-E)$ hysteresis loops indicated that a small amount of $\mathrm{Cu}^{2+}$ addition affected the properties obviously. The results revealed that the addition of $\mathrm{Cu}^{2+}$ significantly improved the sinterability of BCZT ceramics which resulted in a reduction of sintering temperature from $1440{ }^{\circ} \mathrm{C}$ to $1230{ }^{\circ} \mathrm{C}$. The TG-DSC was analyzed to verify the reaction process of $\mathrm{BCZT}-\mathrm{Cu}^{2+}$ materials. $\left(\mathrm{Ba}_{0.85} \mathrm{Ca}_{0.15}\right)\left(\mathrm{Ti}_{0.9} \mathrm{Zr}_{0.1}\right) \mathrm{O}_{3}$ ceramics with $\mathrm{x}=0.020 \mathrm{Cu}^{2+}$ exhibited good electrical properties: $\varepsilon_{m}=12112, T_{\mathrm{c}}=360 \mathrm{~K}, \varepsilon_{\mathrm{r}}=2614, \tan \delta=0.026, K_{\mathrm{p}}=0.47$ and $d_{33}=382 \mathrm{pC} / \mathrm{N}$. The results indicated that $\mathrm{Cu}^{2+}$-modified BCZT ceramics could be a promising candidate for commercial purposes.
\end{abstract}

Keywords: Sol-gel process; $\mathrm{CuO}$; Dielectric properties; Ferroelectric properties; Impedance analysis 


\section{Introduction}

Lead-based piezoelectric ceramics play a dominant role in the field of piezoelectric materials because their piezoelectric properties are superior to those of lead-free materials ${ }^{[1-3]}$. With the recent growing demand for global environmental protection, the restriction of the use of certain hazardous substances in electrical and electronic equipment (RoHS) directive bans the placing on the EU market of new electrical and electronic equipment containing more than agreed levels of lead in 1 July 2006. Many researchers have greatly focused on lead-free ceramics to replace the lead-based ceramics ${ }^{[4]}$.

Recently, several notable lead-free piezoelectric ceramics have been reported due to their exhibited promising piezoelectric properties ${ }^{[5-8]}$. Among many types of leadfree perovskite ferroelectric, calcium and zirconium co-substituted barium titanate, (1$\mathrm{x})\left(\mathrm{Ba}_{0.7} \mathrm{Ca}_{0.3}\right) \mathrm{TiO}_{3}-\mathrm{xBa}\left(\mathrm{Zr}_{0.2} \mathrm{Ti}_{0.8}\right) \mathrm{O}_{3}$, is regarded as one of the most promising candidate synthesized by the traditional solid state reaction technique by Liu and Ren in 2009, because of its excellent dielectric, piezoelectric and ferroelectric properties ${ }^{[9]}$. A $d_{33}$ value of $600 \mathrm{pC} / \mathrm{N}$ is obtained in $\left(\mathrm{Ba}_{0.85} \mathrm{Ca}_{0.15}\right)\left(\mathrm{Ti}_{0.9} \mathrm{Zr}_{0.1}\right) \mathrm{O}_{3}$ (abbreviated as BCZT) by optimizing sintering temperature at $1540{ }^{\circ} \mathrm{C}^{[10]}$. Hence $\underline{\mathrm{BCZT}}$ ceramics with superior piezoelectric properties reported in literature is presently one of the most important candidate for many piezoelectric applications due to its free nature with a morphotropic phase boundary (MPB) similar to lead based systems ${ }^{[9-14]}$. However the optimal composition with $d_{33}$ value is sintered at high temperature by

solid state reaction method ${ }^{[12,15]}$. Therefore, it is necessary to find an approach to further improve the electrical properties and sintering characters of BCZT ceramics. It is well known that a small amount of suitable addition is an effective and simple 
method to tailor electrical properties of piezoelectric ceramics. $\underline{\mathrm{CuO} \text { was wildly used }}$ as a kind of sintering aid in lead-free ceramics to further improve density and piezoelectric properties such as BNT-BZT ${ }^{[16]}, \mathrm{KNN}^{[17]}$ ceramics, because of its low melting point and formation of the liquid phase. At the same time, it is well known that solid state reaction method requires long reaction times and results in inhomogeneous microstructure, which adversely affects the properties of the system. And also, the wet chemical method, the sol-gel process has shown considerable advantages including excellent chemical stoichiometry, compositional homogeneity, and lower crystallization temperature due to the mixing of liquid precursors on the molecular level ${ }^{[18,19]}$. So the sol-gel method has the possibility of utilizing lower calcination temperatures, which could lead to a lower degree of powder agglomeration and reduce the sintering temperature required, and thus a smaller sintered ceramic grain size can be expected ${ }^{[20]}$. Very few literature has reported on the synthesis of BCZT $+x \mathrm{Cu}^{2+}$ using wet chemical synthesis techniques ${ }^{[21]}$.

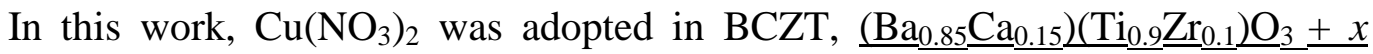

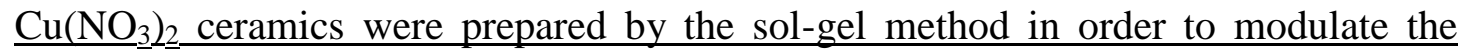
electrical properties and sintering behavior. The dielectric, piezoelectric properties, and complex impedance were investigated.

\section{Experimental procedures}

$$
\left(\mathrm{Ba}_{0.85} \mathrm{Ca}_{0.15}\right)\left(\mathrm{Ti}_{0.9} \mathrm{Zr}_{0.1}\right) \mathrm{O}_{3}+x \mathrm{Cu}^{2+}\left(\mathrm{BCZT}+x \mathrm{Cu}^{2+}\right)(x=0.000,0.010,0.015,
$$

0.020 and 0.025 ) lead-free ceramics were synthesized by sol-gel method. $\mathrm{Ba}\left(\mathrm{CH}_{3} \mathrm{COO}\right)_{2}(99 \%), \mathrm{Ca}\left(\mathrm{CH}_{3} \mathrm{COO}\right)_{2} \cdot \mathrm{H}_{2} \mathrm{O}(99 \%), \mathrm{Zr}\left(\mathrm{NO}_{3}\right)_{4} \cdot 5 \mathrm{H}_{2} \mathrm{O}(99 \%), \mathrm{Ti}\left(\mathrm{OC}_{4} \mathrm{H}_{9}\right)_{4}$ $(\geq 98.0 \%)$ and $\mathrm{Cu}\left(\mathrm{NO}_{3}\right) \cdot 3 \mathrm{H}_{2} \mathrm{O}(99 \%)$ were used as raw materials. Firstly, an appropriate amount of $\mathrm{Ba}\left(\mathrm{CH}_{3} \mathrm{COO}\right)_{2}$ and $\mathrm{Ca}\left(\mathrm{CH}_{3} \mathrm{COO}\right)_{2} \cdot \mathrm{H}_{2} \mathrm{O}$ were dissolved in acetic acid. An appropriate amount of $\mathrm{Zr}\left(\mathrm{NO}_{3}\right)_{4} \cdot 5 \mathrm{H}_{2} \mathrm{O}$ and $\mathrm{Cu}\left(\mathrm{NO}_{3}\right)_{2} \cdot 3 \mathrm{H}_{2} \mathrm{O}$ were 
dissolved in water. Meanwhile, $\mathrm{Ti}\left(\mathrm{OC}_{4} \mathrm{H}_{9}\right)_{4}$ was immixed into ethanol, quickly with vigorously stirring on a magnetic stirrer. Secondly, the three solutions were mixed into a beaker under stirring. After the mixture was heated to form a transparent sol at $50{ }^{\circ} \mathrm{C}$. The sol was then aged for $10 \mathrm{~h}$ at room temperature. Finally, the formed gels were dried at $80{ }^{\circ} \mathrm{C}$ for $72 \mathrm{~h}$. The gels were calcined at $750{ }^{\circ} \mathrm{C}$ for $6 \mathrm{~h}$ to form precursor powders. The precursor powders were press pressed into pellets of $15 \mathrm{~mm}$ diameter under $100 \mathrm{MPa}$ pressure. $\mathrm{BCZT}-x \mathrm{Cu}^{2+}$ ceramics were obtained by sintering the pellets at $1210{ }^{\circ} \mathrm{C}-1300{ }^{\circ} \mathrm{C}$ for $6 \mathrm{~h}$ in air with a heating rate of $2{ }^{\circ} \mathrm{C} / \mathrm{min}$, respectively.

The phase structures of the prepared ceramics samples were characterized by Xray diffraction (XRD, D/max-2200, Rigaku, Japan, $\mathrm{Cu} \mathrm{K} \alpha$ ) with scanning step at $0.02^{\circ}$ and $2 \theta$ range of $20-80^{\circ}$. The microstructures of the natural surface of the asprepared samples were observed with a scanning electron microscopy (SEM, Model Quanta 200, FEI Company, Eindhoven, Netherlands). Silver electrodes were formed on both surfaces of each sintered disk by firing silver at $840{ }^{\circ} \mathrm{C}$ for $30 \mathrm{~min}$. Temperature dependences of dielectric constant were measured on the LCR meter (Agilent E4980A) from ambient temperature to $200{ }^{\circ} \mathrm{C}$ at different frequencies. Low temperature dielectric measurements were carried out with a LCR HiTESTER (HIOKI 3532-50). The samples were placed in a liquid nitrogen cryostat (335 Temperature controller) with temperatures ranging from $80 \mathrm{~K}$ to $350 \mathrm{~K}$. Dielectric dispersion was measured by Agilent 4294A (Palo Alto, CA) impedance analyzer in the frequency range of $300 \mathrm{~Hz}-1 \mathrm{MHz}$ nearby the Curie temperature, respectively. The polarization versus electrical $(P-E)$ hysteresis loops were observed by a Radiant Precision Workstion (Albuquerque, NM, USA). The piezoelectric coefficient $d_{33}$ was measured by a quasistatic piezoelectric meter (ZI-3d, Institute of Acoustic Academic 
Sinica, Beijing, China). The electromechanical coupling coefficient $k_{\mathrm{p}}$ and $Q_{\mathrm{m}}$ were determined by the resonance and antiresonance techniques using an impedance analyzer (HP/Agilent 4294A). Complex impedance were measured by Agilent technologies Inc, 4294A impedance analyzer. Dielectric dispersion were measured by Agilent 4294A (Palo Alto, CA) impedance analyzer in the frequency range of $300 \mathrm{~Hz}$ $-1 \mathrm{MHz}$

\section{Results and discussion}

\subsection{Phase Structure and Microstructure}

To further verify the reaction process of raw powders, TG-DSC analyses of BCZT $-x \mathrm{Cu}^{2+}$ precursor powders are shown in Fig.1. As shown in Fig. 1, lendothermic peak appears in the $100{ }^{\circ} \mathrm{C}$, accompanied by a weight loss in the TG curve. This is related to the volatilization of $\mathrm{H}_{2} \mathrm{O}$ and ethanol. Then, a small endothermic peak appears at about $288^{\circ} \mathrm{C}$, accompanied by a major weight loss in the TG curve. This is related to the main decomposition of nitrates and organic groups in this temperature range. Above $500{ }^{\circ} \mathrm{C}-600{ }^{\circ} \mathrm{C}$, almost no weight loss is found in TG curve, which indicates that noncrystalline oxides slowly react with each other leading to a polycrystalline materiel. The DSC curve shows a small exothermic peak about $660{ }^{\circ} \mathrm{C}$, which may be related to the anatase-rutile transition ${ }^{[22]}$. The DSC curve shows a strong exothermic peak at about $720{ }^{\circ} \mathrm{C}$, which suggests the formation of BCZT phase. The lower phase formation temperature may be due to higher chemical activity and improved crystal growth dynamics resulting from the sol-gel method.

The XRD patterns of BCZT- $x \mathrm{Cu}^{2+}$ ceramics with different $\mathrm{Cu}\left(\mathrm{NO}_{3}\right)_{2}$ additions are shown in Fig.2. It is apparent that all samples exhibit a pure perovskite structure without any trace of impurity phase in Fig. 2(a), implying that $\mathrm{Cu}$ ions diffuse into BCZT lattices and a solid solution forms in the ceramics. In order to further analyze 
the effect of $\mathrm{Cu}^{2+}$ content on the crystal lattice, Fig. 2(b) plots the fine scanning XRD patterns in the $2 \theta$ range from $44^{\circ}$ to $47^{\circ}$ for all samples. In general, the reflections at 45 of $\mathrm{BaTiO}_{3}$ ceramics can be divided into three peaks corresponding to tetragonal (002)/(200), rhombohedral (200) and orthorhombic (200/220). As shown in Fig. 2(b), the sample of $0.00 \leq x \leq 0.010$ reflection intensity of $(200) /(220)$ suggests the emergence of orthorhombic phase. While the specimen of $x=0.015$ shows the coexistent phase of tetragonal and orthorhombic phase. Then the sample of $0.020 \leq x$ $\leq 0.025$ shows the reflection intensity of $(002) /(200)$, meaning the present of single tetragonal phase. It can also be seen that the positions of peaks of BCZT ceramics are shifted to a high angle with an increase in $\mathrm{CuO}$ contents, owing to the partial substitution of $\mathrm{Cu}^{2+}$ occupying B site ${ }^{[23]}$. It is expected from the tolerance factors ${ }^{[24]}$. That small ions $\left[r\left(R^{3+}\right)<0.087 \mathrm{~nm}\right]$ will occupy the $B$ site, large ions $\left[r\left(R^{3+}\right)>0.094\right.$ $\mathrm{nm}$ ] will occupy the A site, and intermediate ions will occupy both sites with different partitioning for each ion. According to $\mathrm{Cu}^{2+}(\mathrm{r}=0.057 \mathrm{~nm})$, there are possibilities for $\mathrm{Cu}^{2+}$ to occupy B site, resulting in a change for the lattice parameter.

Figs. 3(a)-(e) show SEM micrographs of BCZT- $x \mathrm{Cu}^{2+}$ ceramics sintered at $1440{ }^{\circ} \mathrm{C}(x=0.000), 1300{ }^{\circ} \mathrm{C}(x=0.010), 1280{ }^{\circ} \mathrm{C}(x=0.015), 1230{ }^{\circ} \mathrm{C}(x=0.020)$ and $1210{ }^{\circ} \mathrm{C}(x=0.025)$. It can be seen that the introduction of $\mathrm{Cu}^{2+}$ has an evident effect on the grain size and dense microstructure. The pure BCZT ceramics have a homogeneous and big grain relatively, as shown in Fig. 3(a). However, when a small amount of $\mathrm{Cu}^{2+}$ is added, the grain size of ceramics change small at $x=0.015$, then increase sharply at $x=0.020$, and finally change non-uniformity of grains at $x=0.025$. The lower sintering temperature of BCZT here could be partly attributed to the formation of $\mathrm{CuO}-\mathrm{BaO}$ transient liquid phase (eutectic point $\sim 925^{\circ} \mathrm{C}$ ) during the earlier sintering process. Moreover, which is also beneficial to the mass transport 
during sintering and could further promote the grain growth of BCZT. During sintering of BCZT- $x \mathrm{Cu}^{2+}$ ceramics, $\mathrm{Cu}^{2+}$ substitution for $\mathrm{Ti}^{4+}$ and $\mathrm{Zr}^{4+}$ leads to the

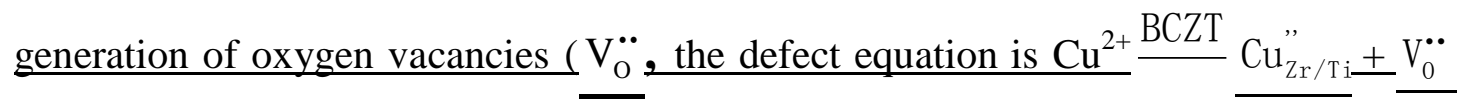
$+\mathrm{TiO}_{2}\left(\mathrm{ZrO}_{2}\right)$. Sr vacancies could be generated accompanied with the appearance of additional oxygen vacancies to maintain charge balance, which would, in turn, enhance mass transport and energy between reactants, thus improving the sintering behavior and inducing grain growth ${ }^{[10]}$. The relative density of $\mathrm{BCZT}-\mathrm{xCu}^{2+}$ ceramics is illustrated in Fig. 3(f). The relative density increases with the increase in $x$ and a minimum value in the density curve appears at $x=0.015$. The surface micrographs of $\underline{\mathrm{BCZT}-x \mathrm{Cu}^{2+}(x=0.020) \text { ceramics are similarity to the pure BCZT ceramics, }}$ indicating that $\mathrm{Cu}$-rich liquid phase (s) segregated at the grains boundaries when the $\underline{\mathrm{Cu} \text { content is greater than its solid solubility limit in crystal structure in the ceramics }}$ with further increasing $\mathrm{x}$ above 0.15. A larger amount of the intergranular liquid phase(s) may result in voids and inhibit both densification and grain growth of the ceramics ${ }^{[10,23]}$. So, it is believed that a small amount of $\mathrm{Cu}^{2+}$ addition to BCZT ceramics can modify the microstructure and the size of the BCZT ceramics, resulting in a reduction of sintering temperature.

\subsection{Dielectric, Ferroelectric and Piezoelectric Properties}

Fig. 4(a) and (b) shows the temperature dependence of dielectric constant and dielectric loss for BCZT- $x \mathrm{Cu}^{2+}$ ceramics measured at $10 \mathrm{kHz}$. As can be seen, three peaks are observed on the dielectric constant and dielectric loss curves of pure BCZT ceramics, two obvious phase transitions above room temperature (321 k and $370 \mathrm{k}$ ) corresponding to the orthorhombic-tetragonal $\left(T_{\mathrm{O} \rightarrow \mathrm{T}}\right)$ and tetragonal-cubic $\left(T_{\mathrm{T} \rightarrow \mathrm{C}}\right)$, and one obvious phase transitions under room temperature (280K) corresponding to 
the rhombohedral-orthorhombic $\left(T_{\mathrm{R} \rightarrow \mathrm{O}}\right)$. However, two types of dielectric constant and loss anomaly are clearly observed in BCZT- $x \mathrm{Cu}^{2+}$ ceramics $(x=0.010,0.015$, $0.020,0.025)$, these two peaks correspond to the polymorphic phase transitions orthorhombic phase to tetragonal phase $\left(T_{\mathrm{O} \rightarrow \mathrm{T}}\right)$ and tetragonal phase to cubic phase $\left(T_{\mathrm{T} \rightarrow \mathrm{C}}\right)$. Fig. 4(c) plots the $\varepsilon_{\mathrm{m}}$ and $T_{\mathrm{T} \rightarrow \mathrm{C}}\left(T_{\mathrm{C}}\right)$ for the BCZT- $x \mathrm{Cu}$ ceramics with different $x$. As can be seen, with increasing $x(x=0.010,0.015,0.020,0.025)$, the dielectric constant in the Curie temperature $T_{\mathrm{C}}\left(\varepsilon_{\mathrm{m}}\right)$ increases initially, reaches the maximum value at $x=0.020$, and then decreases sharply at $x=0.025$. The $T_{\mathrm{C}}$ values of BCZT- $x \mathrm{Cu}^{2+}$ ceramics gradually decrease from $370 \mathrm{~K}$ to $345 \mathrm{~K}$ with the increase of $\mathrm{Cu}$ composition. In addition, the $T_{\mathrm{C}}$ transition peaks slightly shift to low temperature for $x=0.000-0.025$. Furthermore, it can be obviously seen that curve shapes near the Curie peak present a gradually broadening trend with the addition of $\mathrm{Cu}^{2+}$, indicating that the ceramics undergo a ferroelectric-paraelectric diffuse phase transition $(\mathrm{DPT})^{[25]}$. To investigate the degree of the DPT, the modified Curie-Weiss law has been introduced to describe the relaxation behavior ${ }^{[26]}$ :

$\frac{1}{\varepsilon_{\mathrm{r}}}-\frac{1}{\varepsilon_{\max }}=\frac{\left(T-T_{\max }\right)^{\gamma}}{C}$

where $\varepsilon_{\max }$ is the maximum value of the dielectric constant, $\varepsilon_{\mathrm{r}}$ is the dielectric constant at temperature $T, T_{\max }$ is the temperature at the peak of the dielectric constant, $\mathrm{C}$ is the Curie-Weiss constant, and $\gamma$ is the degree of diffuseness, taking the values between 1 (normal ferroelectric) and 2 (ideal relaxor ferroelectric). Fig. 4(d) shows the plots of $\ln \left(1 / \varepsilon_{\gamma}-1 / \varepsilon_{\max }\right)$ as a function of $\ln \left(T-T_{\max }\right)$ at $10 \mathrm{kHz}$ for the BCZT- $x \mathrm{Cu}^{2+}$ ceramics. It can be seen that a linear relationship is observed in all specimens. While the samples for $0.000 \leq x \leq 0.015$, with the addition of $\mathrm{Cu}^{2+}$, the $\gamma$ values increase from 1.529 to 1.750 . However, when the $\mathrm{Cu}^{2+}$ content is $0.020, \gamma$ down to 1.664 , and 
increasing sharply at $x=0.025$. The phenomenon indicates that the addition of $\mathrm{Cu}^{2+}$ will enhance the dielectric diffuse transition behavior of BCZT ceramics. In order to further confirm the characteristic dielectric-frequency-dependence behavior of BCZT$x \mathrm{Cu}$ ceramics associated with structural evolution, the frequency dependence of dielectric properties have been measured. Fig. 5 shows the frequency dependence of dielectric properties for BCZT- $x \mathrm{Cu}^{2+}$ ceramics measured around $\underline{T}_{\mathrm{c}}$ in the frequency range from $100 \mathrm{~Hz}$ to $1 \mathrm{MHz}$. It can be seen that $\varepsilon$ increases gradually until $\underline{T}_{\underline{c}}$, then decreases after $\underline{T}_{\mathrm{c}}$ in the measured frequency range at all samples.

Fig. 6(a) depicts the polarization-electric field $(P-E)$ hysteresis loops of the BCZT- $x \mathrm{Cu}^{2+}$ ceramics as a function of $\mathrm{x}$ from 0.000 to 0.0250 which are measured at $1 \mathrm{~Hz}$ under an electrical field of $30 \mathrm{kV} / \mathrm{cm}$ near room temperature. The ferroelectric properties strongly depend on $\mathrm{Cu}^{2+}$ content in BCZT ceramics. The varying remnant polarization $\left(P_{\mathrm{r}}\right)$ and coercive field $\left(E_{\mathrm{c}}\right)$ are shown in Fig. $6(\mathrm{~b})$. It can be seen that the pure BCZT ceramics exhibit an excellent ferroelectric polarization hysteresis loop, and the $P-E$ loops become deteriorative with increasing $x . E_{\mathrm{c}}$ increases sharply initially until $x=0.015$ to $2.82 \mathrm{kV} / \mathrm{cm}$, then drops sharply at $x=0.020$ to $1.55 \mathrm{kV} / \mathrm{cm}$, and finally increases. Whereas $P_{\mathrm{r}}$ decreases initially, reaches the minimum value at $x$ $=0.015$ to $1.48 \mu \mathrm{C} / \mathrm{cm}^{2}$, and then increases until $x=0.020$ to $5.28 \mu \mathrm{C} / \mathrm{cm}^{2}$, and the finally decrease. It is well known that high $P_{\mathrm{r}}$ and low $E_{\mathrm{c}}$ may be ascribed to the coexistence of orthorhombic and tetragonal phases. Generally speaking, large remnant polarization usually facilitates the piezoelectric properties of the ceramics ${ }^{[27]}$. As can be seen, the ferroelectric hysteresis loops are very slim and like to the ferroelectric hysteresis loops of BT crystal ceramics that have fine grain and suitable grain size ${ }^{[28]}$ at $x=0.015$. The sample of $x=0.025$ displays abnormal and slim ferroelectric $P-E$ hysteresis loops, because that the $\underline{T}_{\mathrm{c}}$ of $x=0.025$ is lower (345 k). 
Table I summarizes the piezoelectric, dielectric and ferroelectric properties of the $\mathrm{BCZT}-x \mathrm{Cu}^{2+}(\mathrm{x}=0.000,0.010,0.015,0.020$ and 0.025$)$ ceramics by means of solgel. $\left(\mathrm{Ba}_{0.85} \mathrm{Ca}_{0.15}\right)\left(\mathrm{Ti}_{0.9} \mathrm{Zr}_{0.1}\right) \mathrm{O}_{3}-0.020 \mathrm{Cu}$ ceramics sintered at $1230{ }^{\circ} \mathrm{C}$ exhibit some new improvement, the results are as follows: $\varepsilon_{m}=12112, T_{\mathrm{c}}=360 \mathrm{~K}, \varepsilon_{\mathrm{r}}=2614, \tan \delta=$ $0.026, K_{\mathrm{p}}=0.47$ and $d_{33}=382 \mathrm{pC} / \mathrm{N}$. As is mentioned above, the defect dipoles have a pinning effect on the motion of ferroelectric domain wall, which in turn increase the coercive field $E_{\mathrm{c}}$ and reduce the remnant polarization $P_{\mathrm{r}}$. The enhancement of the ferroelectricity could also be attributed to the easier polarization reversal process of ferroelectric domain in larger grains than in fine grains. In addition, the dense, $\underline{\text { homogeneous microstructure and enlarged grain size for optimal electrical properties, }}$ which is benefited from the $\mathrm{CuO}-\mathrm{BaO}$ liquid phase sintering. And the occurrence of orthorhombic-tetragonal phase transition near room temperature and the relatively $\underline{\text { lower }} E_{\mathrm{c}}$ are also beneficial to the high piezoelectric performance ${ }^{[10,16,17,21,23]}$. The results indicate that $\mathrm{Cu}^{2+}$-modified $\mathrm{BCZT}$ ceramics could be a promising candidate for commercial purposes.

\subsection{Impedance Analysis}

It's well known that electrical properties of the polycrystalline ceramics are strongly affected by their microstructures ${ }^{[29,30]}$. In electroceramics, the grain boundaries are normally more insulating and capacitive than grains (bulk) mainly due to the presence of dangling bonds and non-stoichiometric distribution of oxygen on the grain boundaries, which act as barrier layers and charge carrier traps ${ }^{[31]}$. The response of the grain boundaries lies generally at higher frequencies than electrodesemiconductor contacts but lower than the grains (bulk) ${ }^{[31,32]}$. The complex impedance plot of BCZT $-x \mathrm{Cu}^{2+}$ ceramics with different $\mathrm{Cu}^{2+}$ additions at $380{ }^{\circ} \mathrm{C}$ are shown in Fig. 7(a). In the complex impedance spectra of ideal polycrystalline ceramics the first 
semicircle in the range of high frequency suggests the grain interior, the second semicircle in the range of middle frequency reflects the grain boundary effects and the third semicircle in the range of low frequency reflects the ceramic-electrode interface effects ${ }^{[33]}$. It can be seen that all samples show two semicircles, the first depressed semicircle at high frequency, is representative of bulk response. The second semicircle in the low frequency is due to the grain-boundary effect. This result indicates that $\mathrm{BCZT}-\mathrm{Cu}^{2+}$ ceramics are heterogeneously consisting of semiconducting grains and insulating grain boundaries ${ }^{[34]}$.

To evaluate the activation energy of the relaxation processes inside the grains, the relaxation frequency associated with these peaks follows the Arrhenius law in the temperature range and the expression can be described ${ }^{[35]}$

$f_{\max }=f_{0} \exp \left(\frac{E_{\mathrm{a}}}{K_{\mathrm{B}} T}\right)$

where $f_{\max }$ is the peak frequency, $f_{0}$ is the preexponential term, $E_{\mathrm{a}}$ is the relaxation activation energy, and $\mathrm{k}$ is the Boltzmann constant. A plot of $\ln f_{\max } \mathrm{vs} 1000 / \mathrm{T}$ is shown in Figs. 7(b)-(f). It is reported by Waser ${ }^{[36]}$ that the oxygen vacancies can move at higher temperature in $\mathrm{SrTiO}_{3}$ due to the thermal activation, with energy of 1.005$1.093 \mathrm{eV}$, and give rise to conduction. Whereas, the relaxation activation energy observed in our samples is $\underline{0.97 \sim 1.126 \mathrm{eV}}$, which appears to be too high to attribute to the aforementioned mechanism. The other alternative is the space-charge model which points out that the free charges move through the sample toward the electrode of opposite sign in the presence of the external electric field and constitute a macrodipole ${ }^{[37]}$. Therefore, its oscillations with external ac field give rise to relaxation and conduction processes. Maglione et al explained dielectric relaxation phenomena in several perovskite materials based on space-charge model ${ }^{[38]}$. They found that the relaxation activation energies of space charge were around 1.17-1.48 
$\mathrm{eV}$ and the conduction activation energies were in the range of $1.07-1.31 \mathrm{eV}$ for Ladoped $\mathrm{PbTiO}_{3}$.

Fig. 8 presents the variation of the imaginary ( $\left.Z^{\prime \prime}\right)(a)$ and real $\left(Z^{\prime}\right)(b)$ part of the impedance (impedance loss spectrum) with frequency for BCZT- $x \mathrm{Cu}^{2+}$ ceramics $(\mathrm{x}=$ $0.000,0.010,0.015,0.020$ and 0.025$)$ at $380{ }^{\circ} \mathrm{C}$. This representation allows one to obtain information on the electrical processes having the largest resistance according to the relations $Z^{\prime}=R /\left[1+(\omega R C)^{2}\right]$ and $Z^{\prime \prime}=\omega R^{2} C /\left[1+(\omega R C)^{2}\right]$. The appearance of well-defined peaks in the $Z^{\prime \prime}(f)$ dependence is an indication of the beginning of electrical relaxation in the material ${ }^{[39]}$. In turn, the asymmetric broadening of the peaks points out to the presence of electrical processes in the material with spread of relaxation time at two equilibrium positions ${ }^{[40]}$. The dependence of the real part of the impedance $\left(Z^{\prime}\right)$ on the frequency at $380{ }^{\circ} \mathrm{C}$ for all the samples has been shown in Fig. 10(b). It is observed that the real part of the impedance (i.e., resistance) increases abruptly at a $\mathrm{Cu}^{2+}$ concentration dependent frequency. The decrease in de value of $\mathrm{Z}^{\prime}$ suggests that the ac conductivity increases with increasing frequency.

\section{Conclusions}

The $\mathrm{Cu}^{2+}$-modified $\left(\mathrm{Ba}_{0.85} \mathrm{Ca}_{0.15}\right)\left(\mathrm{Ti}_{0.9} \mathrm{Zr}_{0.1}\right) \mathrm{O}_{3}$ ceramics $(\mathrm{x}=0.00-0.025)$ were synthesized by the sol-gel method. The addition of $\mathrm{Cu}^{2+}$ and the sol-gel method were favorable for densification and lower sintering temperature of the ceramics. The microstructure, dielectric, ferroelectric, piezoelectric properties, and impedance behaviors of $\mathrm{Cu}^{2+}$-modified $\left(\mathrm{Ba}_{0.85} \mathrm{Ca}_{0.15}\right)\left(\mathrm{Ti}_{0.9} \mathrm{Zr}_{0.1}\right) \mathrm{O}_{3}$ ceramics have been investigated systematically. X-ray diffraction analysis revealed that single perovskite phase was obtained in all compounds. The impedance spectroscopy of these samples well separated the grain and grain boundary regions. 


\section{Acknowledgments}

This work was supported by National Science Foundation of China (NSFC) (Grant Nos. 51577111, 51572163 and 51107077), the Fundamental Research Funds for the Central Universities (Program Nos. GK201601003, GK201402061 and GK201403006), Science and Technology Program of Shaanxi Province (Grant No. 2013K09-26 and 2015JZ011), and Information Materials and Devices Research Center of the Shanghai Institute of Ceramics of the Chinese Academy of Sciences (SICCAS) (KLIFMD-2015-04). 


\section{References}

[1] Y. Saito, H. Takao, T. Tani, T. Nonoyama, K. Takatori, T. Homma, T. Nagaya, M. Nakamura, Lead-free at last, Materials science, Nature, 432(2004) 84-87.

[2] X. C. Wang, T. Q. Yang, J. Shen, Y. Dong, Y. Z. Liu, Phase transition and dielectric properties of $(\mathrm{Pb}, \mathrm{La})(\mathrm{Zr}, \mathrm{Sn}, \mathrm{Ti}) \mathrm{O}_{3}$ ceramics at morphotropic phase boundary, J. Alloy Compd., 673 (2016) 67-72.

[3] R. Nie, Q. Zhang, Y. Yue, H. Liu, Y. B. Chen, Q. Chen, J. G. Zhu, P. Yu, D. Q. Xiao, Phase structure-electrical property relationships in $\mathrm{Pb}\left(\mathrm{Ni}_{1 / 3} \mathrm{Nb}_{2 / 3}\right) \mathrm{O}_{3}-\mathrm{Pb}(\mathrm{Zr}$, Ti)O $\mathrm{O}_{3}$-based ceramics, J. Appl. Phys., 119 (2016) 124111.

[4] P. Kantha, K. Pengpat, P. Jarupoom, U. Intatha, G. Rujijanagul,T. Tunkasiri, Phase formation and electrical properties of BNLT-BZT lead-Free piezoelectric ceramic system, Curr. Appl. Phys., 9 (2009) 460-466.

[5] E. Hollenstein, M. Davis, D. Damjanovic, N. Setter, Piezoelectric properties of Liand Ta-modified $\left(\mathrm{K}_{0.5} \mathrm{Na}_{0.5}\right) \mathrm{NbO}_{3}$ ceramics, Appl. Phys. Lett., 87 (2005) 182905.

[6] X. L. Chao, J. J. Wang, P. F. Liang, T. Zhang, L. L. Wei, Z. P. Yang, Phase transition and improved electrical performance of $\mathrm{Ba}_{0.85} \mathrm{Ca}_{0.15} \mathrm{Zr}_{0.1} \mathrm{Ti}_{0.9} \mathrm{O}_{3}-$ $\mathrm{Ca}_{0.28} \mathrm{Ba}_{0.72} \mathrm{Nb}_{2} \mathrm{O}_{6}$ ceramics with high Curie temperature, Mater. Design., 89 (2016) $465-469$.

[7] D. M. Lin, D. Q. Xiao, J. G. Zhu, P. Yu, Piezoelectric and ferroelectric properties of $\mathrm{Bi}_{0.5}\left(\mathrm{Na}_{1-\mathrm{x}-\mathrm{y}} \mathrm{Bi}_{\mathrm{x}} \mathrm{Li}_{\mathrm{y}}\right)_{0.5} \mathrm{TiO}_{3}$ lead-free piezoelectric ceramics, Appl. Phys. Lett., 88 (2006) 062901.

[8] D. Z. Xue, Y. M. Zhou, H. X. Bao, J. H. Gao, C. Zhou, X. B. Ren, Large piezoelectric effect in $\mathrm{Pb}$-free $\mathrm{Ba}(\mathrm{Ti}, \mathrm{Sn}) \mathrm{O}_{3}-\mathrm{x}(\mathrm{Ba}, \mathrm{Ca}) \mathrm{TiO}_{3}$ ceramics, Appl. Phys. Lett., 99 (2011) 122901. 
[9] W. F. Liu, X. B. Ren, Large piezoelectric effect in Pb-free ceramics, Phys. Rev. Lett., 103 (2009) 257602.

[10] H. J. Sun, Y. Zhang, X. F. Liu, Y. Liu, W. Chen, Effects of $\mathrm{CuO}$ additive on $\underline{\text { structure and electrical properties of low-temperature sintered }}$

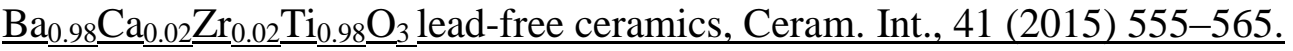

[11] W. Li, Z. J. Xu, R. Q. Chu, P. Fu, G. Z. Zang, Piezoelectric and dielectric

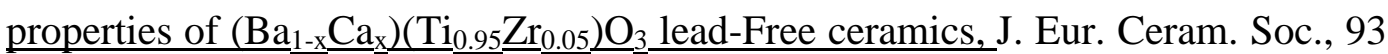
[10] (2010) 2942-2944.

[12] H. X. Bao, C. Z. Hou, D. Z. Xue, J. H. Gao, X. B. Ren, A modified lead-free piezoelectric BZT-xBCT system with higher $T_{\mathrm{C}_{2}}$ Journal of Physics D: Applied Physics., 43 (2010) 465401.

[13] H. J. Sun, S. H. Duan, X. F. Liu, D. W. Wang, H. T. Sui, Lead-free $\underline{\mathrm{Ba}_{0.98}} \underline{\mathrm{Ca}_{0.02}} \underline{\mathrm{Zr}}_{0.02} \underline{\mathrm{Ti}}_{0.98} \underline{\mathrm{O}}_{3}$ Ceramics with Enhanced Electrical Eerformance by

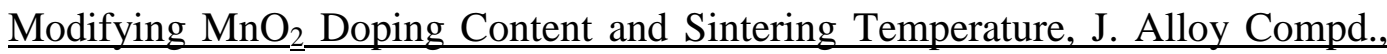
$\underline{670(2016) 262-267 .}$

[14] Z. M. Wang, J. J. Wang, X. L. Chao, L. L. Wei, B. Yang, D. W. Wang, Z. P. Yang, Synthesis, structure, dielectric, piezoelectric, and energy storage performance of $\left(\mathrm{Ba}_{0.85} \underline{\mathrm{Ca}}_{0.15}\right)\left(\mathrm{Ti}_{0.9} \underline{\mathrm{Zr}}_{0.1} \underline{\mathrm{O}}_{3}\right.$ ceramics prepared by different methods, J. Mater. Sci: Mater. Electron., 27 (2016) 5047-5058.

[15] J. Gao, D. Xue, Y. Wang, D. Wang, L. Zhang, H. Wu, Microstructure basis for strong piezoelectricity in $\mathrm{Pb}$-free $\mathrm{Ba}\left(\mathrm{Zr}_{0.2} \mathrm{Ti}_{0.8}\right) \mathrm{O}_{3}-\left(\mathrm{Ba}_{0.7} \mathrm{Ca}_{0.3}\right) \mathrm{TiO}_{3}$ ceramics. Appl. Phys. Lett., 99 (2011) 092901.

[16] H. Y. Tian, K. W. Kwok, H. L.W. Chan, The effects of CuO-doping on dielectric and piezoelectric properties of $\mathrm{Bi}_{0.5} \mathrm{Na}_{0.5} \mathrm{TiO}_{3}-\mathrm{Ba}\left(\mathrm{Zr}\right.$, Ti) $\mathrm{O}_{3}$ lead-free ceramics. $\mathrm{J}$. Mater. Sci., 42 (2007) 9750-9755. 
[17] D. Y. Liang, X. H. Zhu, J. L. Zhu, J. G. Zhu, D. Q. Xiao, Effects of CuO addition on the structure and electrical properties of low temperature sintered $\mathrm{Ba}(\mathrm{Zr}, \mathrm{Ti}) \mathrm{O}_{3}$ lead-free piezoelectric ceramics, Ceram. Int., 40 (2014) 2585-2592.

[18] C. J. Brinker, G. W. Scherer, The Physics and Chemistry of Sol-gel Processing, Academic Press, New York, 1990.

[19] Y. G. Metlin, Y. D. Tretyakov, Chemical routes for preparation of oxide hightemperature superconducting powders and precursors for super-conductive ceramics, coatings and composites, J. Mater. Chem., 4 (1994) 1659-1665.

[20] J. P. Praveen, K. Kumar, A. R. James, T. Karthik, T. Karthik, S. Asthana, D. Das, Large piezoelectric strain observed in sol-gel derived BZT-BCT ceramics, Curr. Appl. Phys., 14 (2014) 396-402.

[21] J. Li, X. J. Sun, X. S. Zhang, Synthesis and characterization of sol-gel derived $\mathrm{Ba}_{0.85} \mathrm{Ca}_{0.15} \mathrm{Ti}_{0.9} \mathrm{Zr}_{0.1} \mathrm{O}_{3}-\mathrm{xCu}$ ceramics, Phys. Stat. Soli., A. 210 (2013) 533-537.

[22] J. W. Li, P. F. Liang, J. Yi, Phase formation and enhanced dielectric response of $\mathrm{Y}_{2 / 3} \mathrm{Cu}_{3} \mathrm{Ti}_{4} \mathrm{O}_{12}$ ceramics derived from the Sol-Gel process, J. Am. Ceram. Soc., 98 (2015) 795-803.

[23] Y. Cui, X. Y. Liu, M. H. Jiang, Lead-free $\left(\mathrm{Ba}_{0.7} \mathrm{Ca}_{0.3}\right) \mathrm{TiO}_{3}-\mathrm{Ba}\left(\mathrm{Zr}_{0.2} \mathrm{Ti}_{0.8}\right) \mathrm{O}_{3}-x w t \%$ $\mathrm{CuO}$ ceramics with high piezoelectric piezoelectric coefficient by lowtemperature sintering, J. Mater. Sci: Mater. Electron., (2012) 23:1342-1345.

[24] J. G. Wu, D. Q. Xiao, J. G. Zhu, Potassium-sodium niobate lead-free piezoelectric materials: past, present, and future of phase boundaries, Chem. Rev. 115 (2015) 2559-2595.

[25] X. F. Wang, P. F. Liang, X. L. Chao, Z. P. Yang, Dielectric properties and Impedance spectroscopy of $\mathrm{MnCO}_{3}$-modified $\left(\mathrm{Ba}_{0.85} \mathrm{Ca}_{0.15}\right)\left(\mathrm{Ti}_{0.9} \mathrm{Zr}_{0.1}\right) \mathrm{O}_{3}$ lead- 
free ceramics, J. Am. Ceram. Soc., 98 (2015) 1506-1514.

[26] X. J. Chou, J. W. Zhai, X. Yao, Relaxor behavior and dielectric properties of $\mathrm{La}_{2} \mathrm{O}_{3}$-doped barium zirconium titanate ceramics for tunable device applications, Mater. Chem. Phys., 109 (2008) 125-130.

[27] X. F. Wang, P. F. Liang, X. L. Chao, Z. P. Yang, Polymorphic phase transition and enhanced electrical properties of $\left(\mathrm{Ba}_{0.91} \mathrm{Ca}_{0.09-\mathrm{x}} \mathrm{Sr}_{\mathrm{x}}\right)\left(\mathrm{Ti}_{0.92} \mathrm{Sn}_{0.08}\right) \mathrm{O}_{3}$ lead-free ceramics, Ceram. Int., 40 (2014) 9389-9394.

[28] L. Jin, F. Li, S. J. Zhang, Decoding the fingerprint of ferroelectric loops: comprehension of the material properties and structures, J. Am. Ceram. Soc., 97[1] (2014) 1-27.

[29] F. J. Geng, C. H. Yang, P. P. Lv, C. Wei, J. Qian, C. Feng, Q. Yao, X. M. Jiang, P. Song, Microstructure, leakage current and dielectric tunability of $\mathrm{Na}_{0.5} \mathrm{Bi}_{0.5}\left(\mathrm{Ti}_{0.99} \mathrm{Zn}_{0.01}\right) \mathrm{O}_{3}$ thin films: An annealing atmosphere-dependent study, Ceram. Int., 42 (2016) 8744-8749.

[30] Y. Sudo, M. Hagiwara, S. Fujihara, Grain size effect on electrical properties of Mn-modified $0.67 \mathrm{BiFeO}_{3}-0.33 \mathrm{BaTiO}_{3}$ lead-free piezoelectric ceramics, Ceram. Int., 42 (2016) 8206-8211.

[31] I. Ahmad, M. J. Akhtar, M. M. Hasan, Impedance spectroscopic investigation of electro active regions, conduction mechanism and origin of colossal dielectric constant in $\mathrm{Nd}_{1-\mathrm{x}} \mathrm{Sr}_{\mathrm{x}} \mathrm{FeO}_{3}(0.1 \leq \mathrm{x} \leq 0.5)$, Mate. Res. Bull., 60 (2014) 474-484.

[32] A. P. Turygin, M. M. Neradovskiy, N. A. Naumova, D. V. Zayats, I. Coondoo, A. L. Kholkin, V. Y. Shur, Domain structures and local switching in lead-free piezoceramics $\mathrm{Ba}_{0.85} \mathrm{Ca}_{0.15} \mathrm{Ti}_{0.90} \mathrm{Zr}_{0.10} \mathrm{O}_{3}$, J. Appl. Phys. 118 (2015) 072002.

[33] J. Jiang, T. J. Zhang, B. S. Zhang, H. Mao, Complex impedance analysis of 
$\mathrm{Ba}_{0.65} \mathrm{Sr}_{0.35} \mathrm{TiO}_{3}$ ceramics, J. Electroceram., 21 (2008) 258-262.

[34] Q. M. Hang, W. K. Zhou, X. H. Zhu, J. M. Zhu, Z. G. Liu, T. Al-Kassab, Structural, spectroscopic, and dielectric characterizations of Mn-doped $0.67 \mathrm{BiFeO}_{3}-0.33 \mathrm{BaTiO}_{3}$ multiferroic ceramics, J. Adv. Ceram, 2 (2013) 252259.

[35] A. Ansari, A. Nisar, B. Fatma, and W. Khan, Temperature dependence anomalous dielectric relaxation in Co doped $\mathrm{ZnO}$ nanoparticles, Mate. Res. Bull., 47 (2012) 4161-4168.

[36] P. Zheng, J. L. Zhang, Y. Q. Tan, C. L. Wang, Grain-size effects on dielectric and piezoelectric properties of poled $\mathrm{BaTiO}_{3}$ ceramics, Acta. Mater., 60 (2012) $5022-5030$.

[37 ] J. J. Liu, C. G. Duan, W. G. Yin, W. N. Mei, R. W. Smith, J. R. Hardy, Dielectric permittivity and electric modulus in $\mathrm{Bi}_{2} \mathrm{Ti}_{4} \mathrm{O}_{11}$, J. Chem. Phys., 119 [5] (2003) 2812-2819.

[38] O. Bidault, P. Goux, M. Kchikech, M. Belkaoumi, M. Maglione,Space-charge relaxation in perovskites, Phys. Rev. B, 49 (1994) 7868-7873.

[39] J. L. Izquierdo, G. Bolanos, V. H. Zapata, O. Moran, Dielectric relaxation and ac conduction in multiferroic $\mathrm{TbMnO}_{3}$ ceramics: Impedance spectroscopy analysis, Curr. Appl. Phys., 14 (2014) 1492-1497.

[40] K. Brajesh, K. Tanwar, M. Abebe. R. Ranjan, Relaxor ferroelectricity and electric-field-driven structural transformation in the giant lead-free piezoelectric (Ba,Ca)(Ti, Zr)O 3 , Phys. Rev. B, 92 (2015) 224112. 


\section{Figure Captions}

Fig. 1. TG-DSC analyses of BCZT- $x \mathrm{Cu}^{2+}$ precursor powders.

Fig. 2. (a) The XRD patterns of BCZT- $x \mathrm{Cu}^{2+}$ ceramics and (b) the fine scanning XRD patterns in the $2 \theta$ range from range from $44^{\circ}$ to $47^{\circ}$ with different $\mathrm{Cu}\left(\mathrm{NO}_{3}\right)_{2}$ additions. Fig. 3. SEM micrographs of BCZT- $x \mathrm{Cu}^{2+}$ ceramics with $x$ content sintered at different temperature. (a) $1440{ }^{\circ} \mathrm{C}(x=0.000)$, (b) $1300{ }^{\circ} \mathrm{C}(x=0.010)$, (c) $1280{ }^{\circ} \mathrm{C}(x=0.015)$, (d) $1230{ }^{\circ} \mathrm{C}(x=0.020)$, (e) $1210{ }^{\circ} \mathrm{C}(x=0.025)$ and (f) the relative density of BCZT$\mathrm{xCu} \mathrm{Cu}^{2+}$ ceramics.

Fig. 4. The temperature dependence of (a) dielectric constant and (b) dielectric loss for BCZT- $x \mathrm{Cu}^{2+}$ ceramics measured at $10 \mathrm{kHz}$, (c) the $\varepsilon_{\mathrm{m}}$ and $T_{\mathrm{T} \rightarrow \mathrm{C}}\left(T_{\mathrm{C}}\right)$ for the BCZT- $x$ Cu ceramics with different $x$, (d) the plots of $\ln \left(1 / \varepsilon_{\gamma}-1 / \varepsilon_{\max }\right)$ as a function of $\ln \left(T-T_{\max }\right)$ at $10 \mathrm{kHz}$.

Fig. 5. The frequency dependence of dielectric properties for $\mathrm{BCZT}-x \mathrm{Cu}^{2+}$ ceramics measured around $T \mathrm{c}$ as a function of the frequency, (a) $x=0.000$, (b) $x=0.010$, (c) $(x$ $=0.015$, (d) $x=0.020$, (e) $x=0.025$.

Fig. 6. (a) The polarization-electric field $(P-E)$ hysteresis loops, (b) The remnant polarization $\left(P_{\mathrm{r}}\right)$ and coercive field $\left(E_{\mathrm{c}}\right)$ of the BCZT- $x \mathrm{Cu}^{2+}$ ceramics as a function of $\mathrm{x}$ from 0.000 to 0.0250 .

Fig. 7. The complex impedance plot of $\mathrm{BCZT}-x \mathrm{Cu}^{2+}$ ceramics with different $\mathrm{Cu}^{2+}$ additions at $380{ }^{\circ} \mathrm{C}$, (a) $x=0.000$, (b) $x=0.010$, (c) $(x=0.015$, (d) $x=0.020$, (e) $x=$ 0.025 .

Fig. 8. The variation of (a) the imaginary $\left(Z^{\prime \prime}\right)$ and (b) real ( $\left.Z^{\prime}\right)$ part of the impedance (impedance loss spectrum) with frequency for BCZT- $x \mathrm{Cu}^{2+}(\mathrm{x}=0.000,0.010,0.015$, 0.020 and 0.025$)$ at $380{ }^{\circ} \mathrm{C}$.

Table I summarizes the piezoelectric, dielectric and ferroelectric properties of the 
BCZT $-x \mathrm{Cu}^{2+}(\mathrm{x}=0.000,0.010,0.015,0.020$ and 0.025$)$ ceramics by means of sol-gel. 


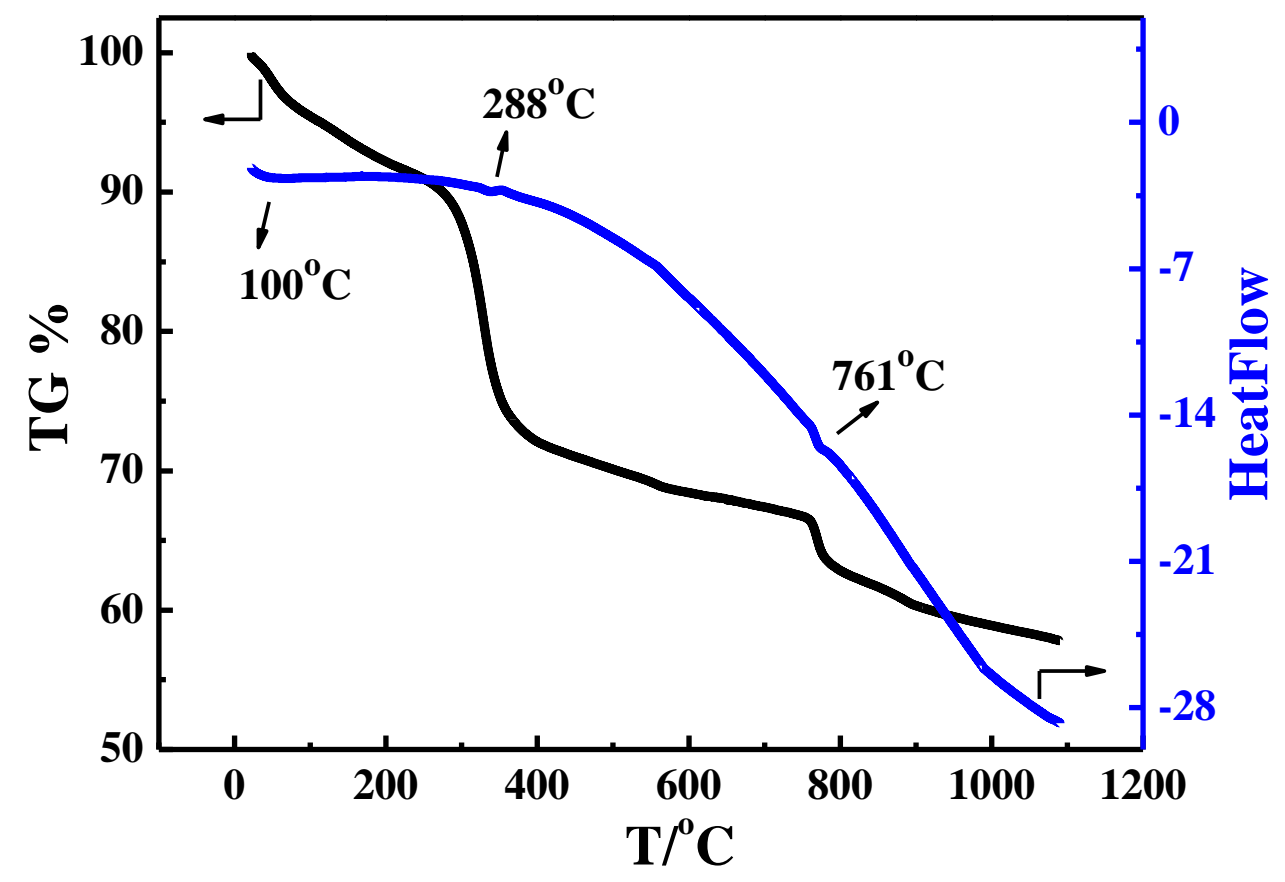

Fig.1. Z. M. Wang, X. L. Chao et al 


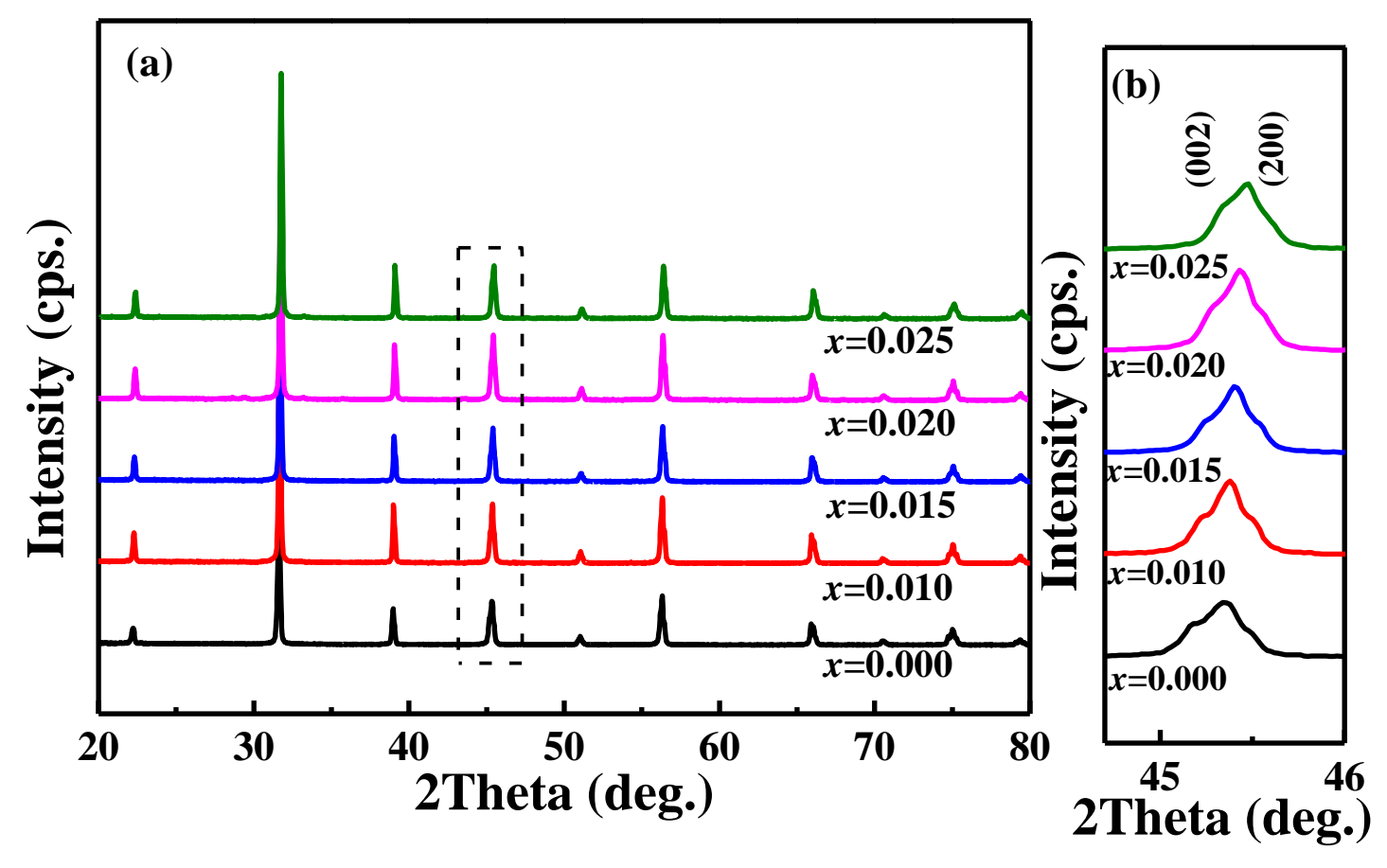

Fig.2. Z. M. Wang, X. L. Chao et al 

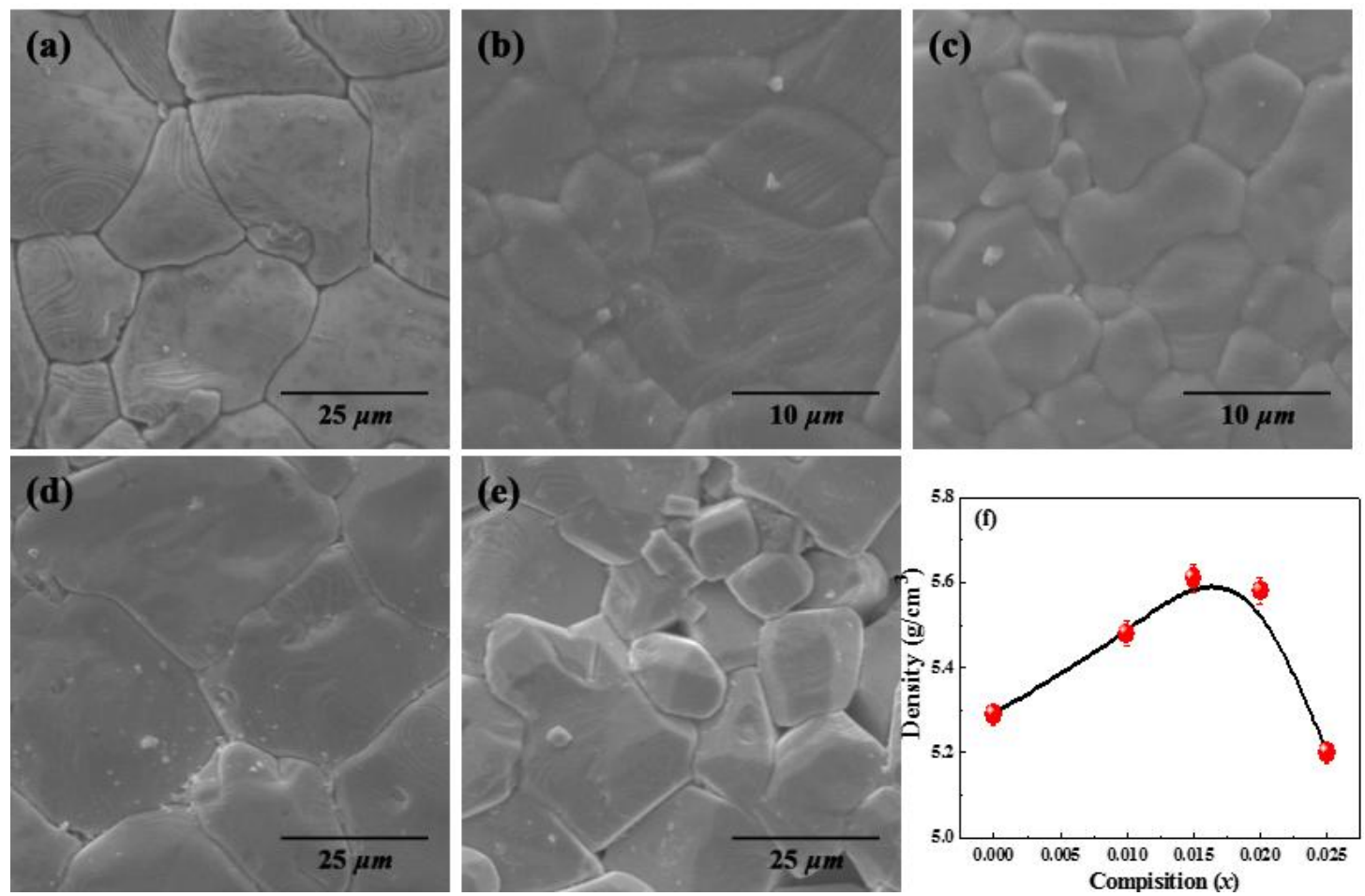

Fig.3. Z. M. Wang, X. L. Chao et al 

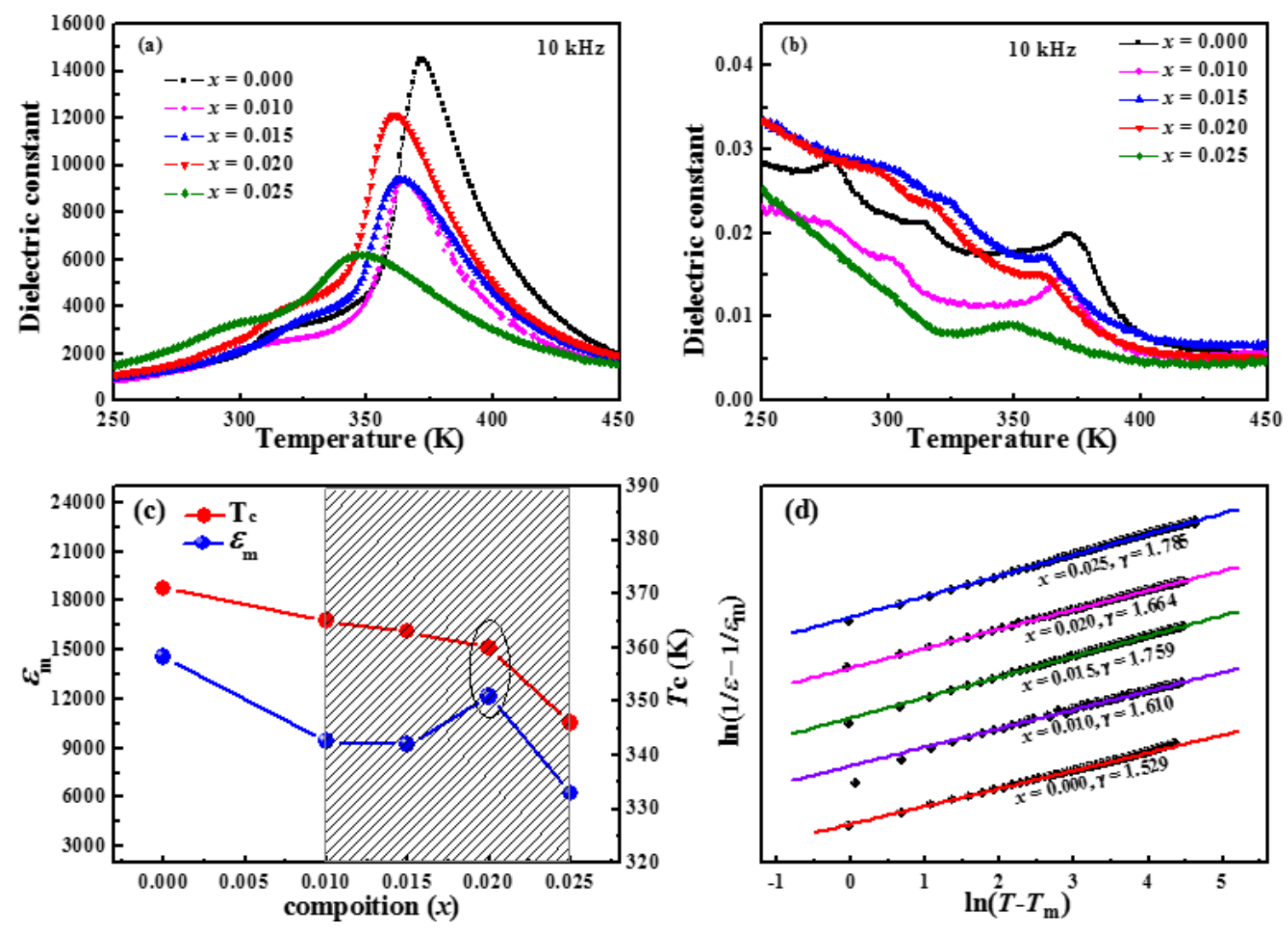

Fig.4. Z. M. Wang, X. L. Chao et al 

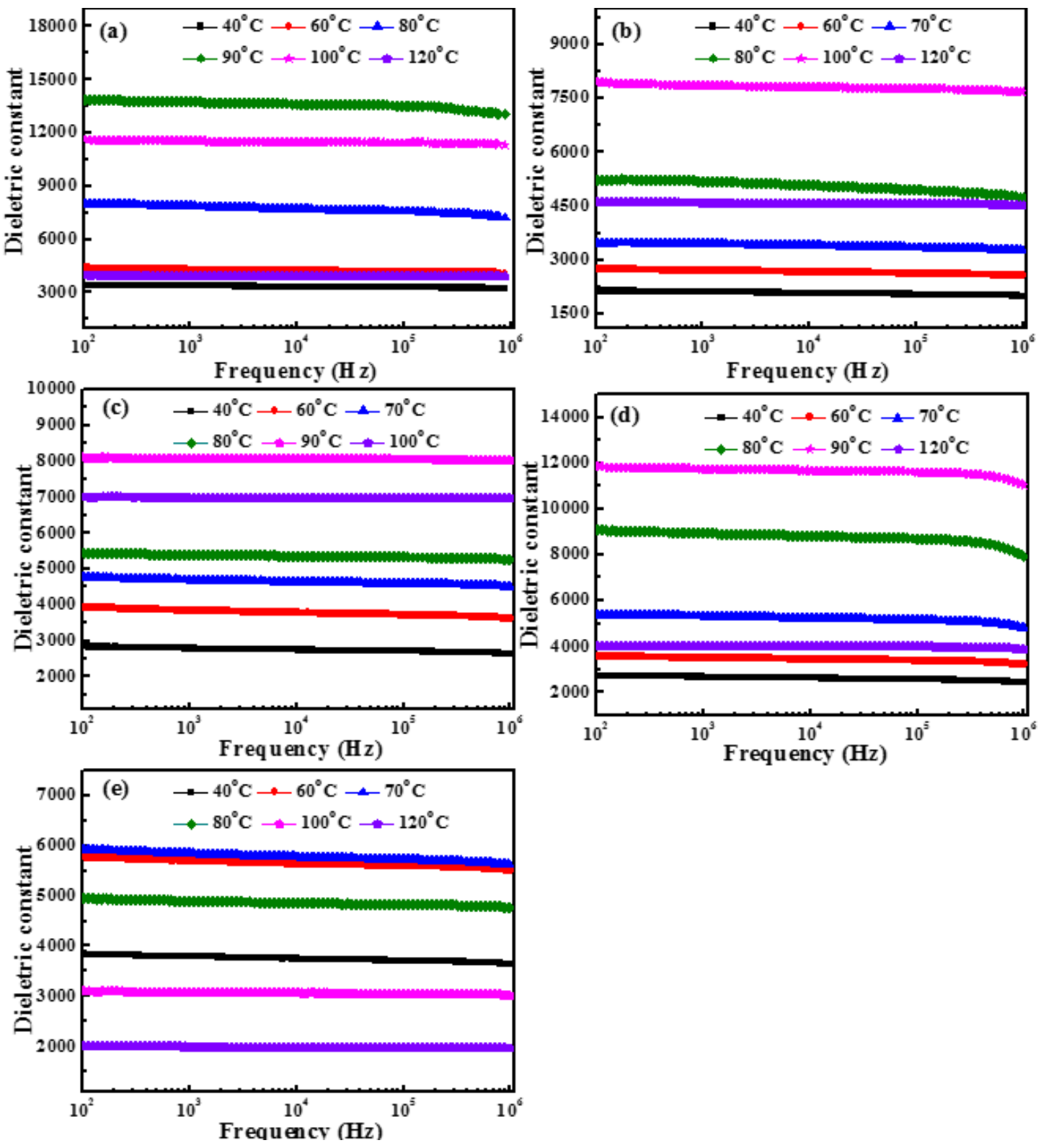

Fig.5. Z. M. Wang, X. L. Chao et al 

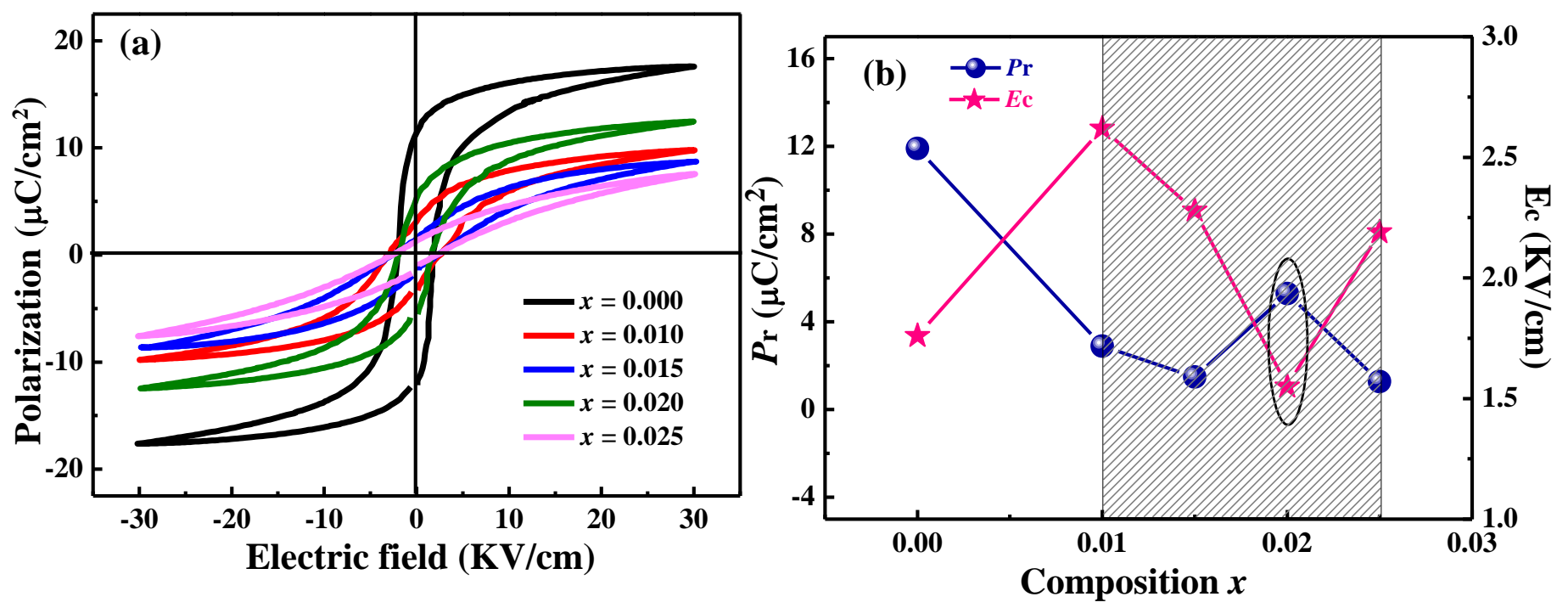

Fig.6. Z. M. Wang, X. L. Chao et al 

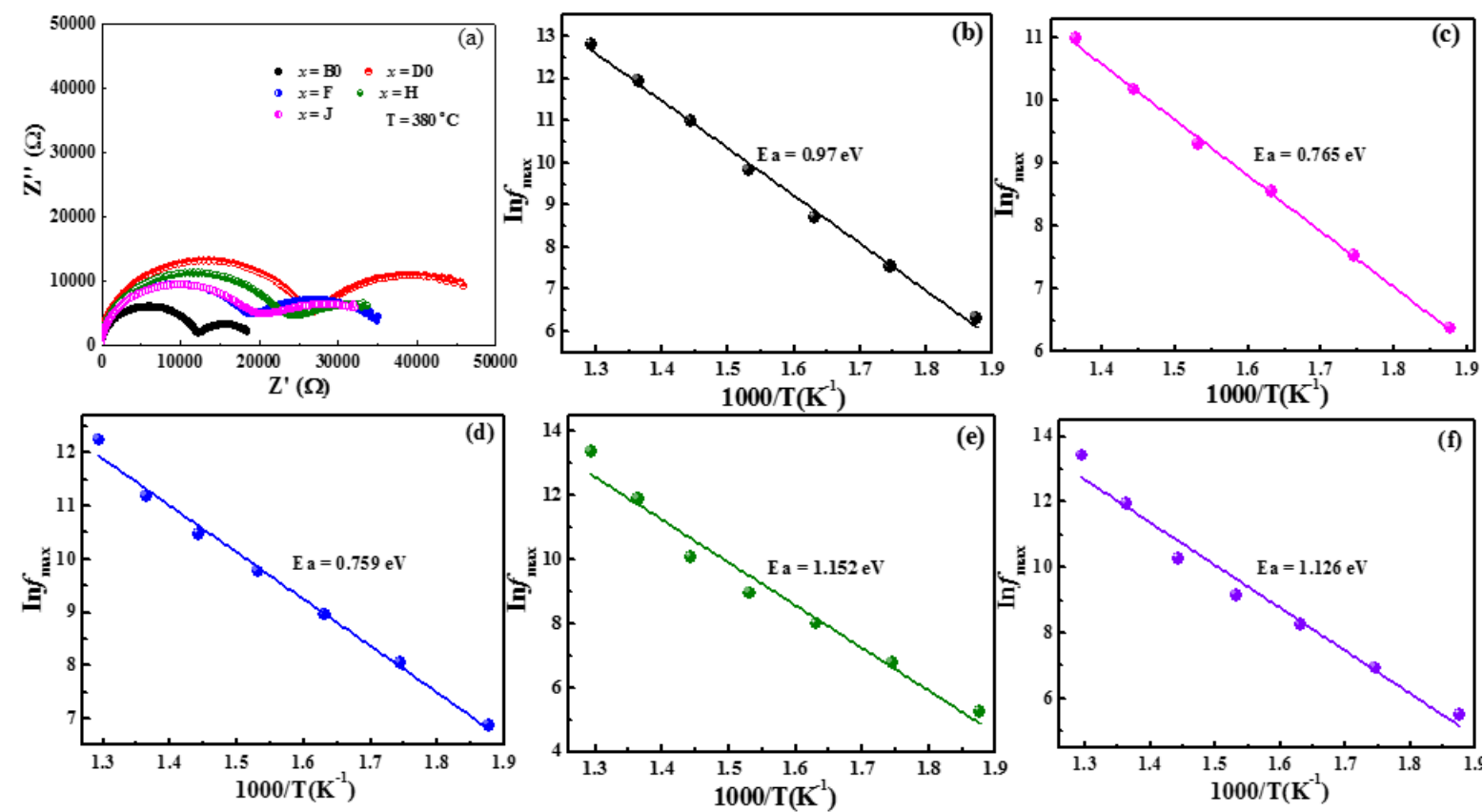

Fig.7. Z. M. Wang, X. L. Chao et al 

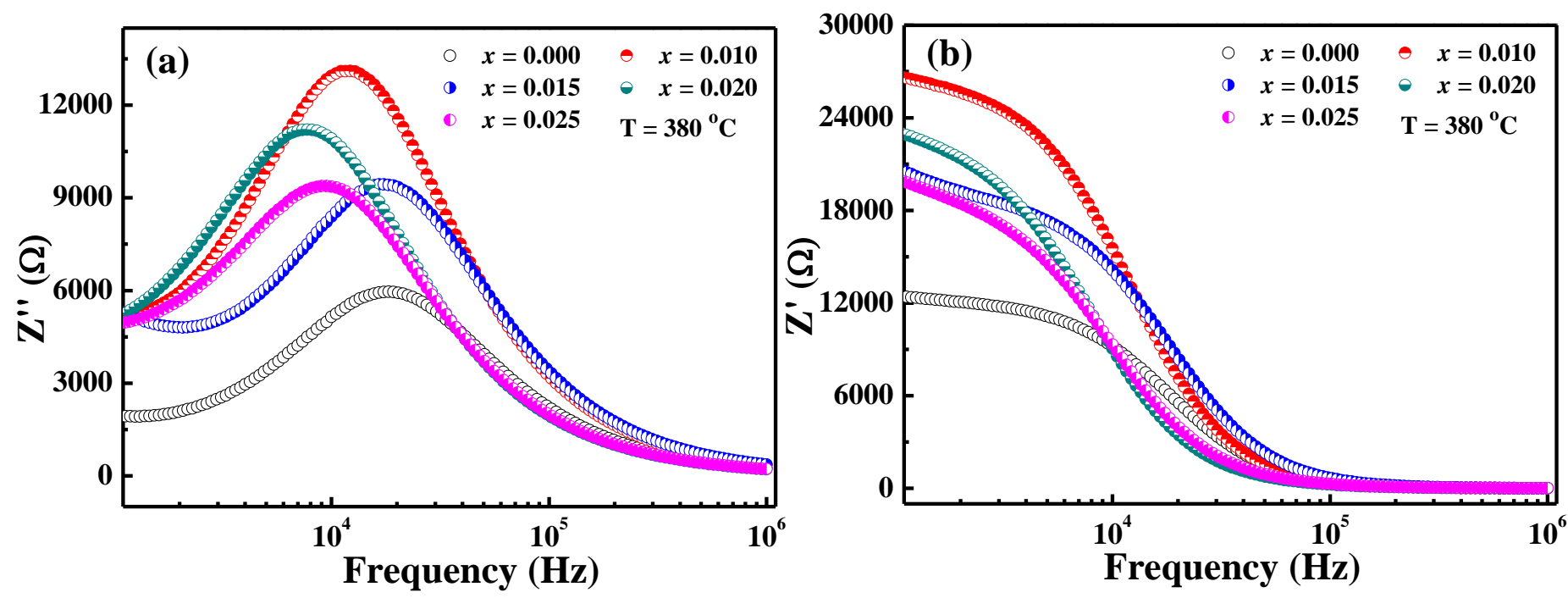

Fig.8. Z. M. Wang, X. L. Chao et al 
Table 1. The piezoelectric, dielectric and ferroelectric properties of BCZT- $x \mathrm{Cu}^{2+}$ ceramics by means of sol-gel.

\begin{tabular}{ccccccccccc}
\hline$x$ & $\mathrm{ST}\left({ }^{\circ} \mathrm{C}\right)$ & $\rho\left(\mathrm{g} / \mathrm{cm}^{3}\right)$ & $d_{33}(\mathrm{pC} / \mathrm{N})$ & $K_{\mathrm{p}}$ & $\tan \delta$ & $\varepsilon_{\mathrm{r}}$ & $\varepsilon_{m}$ & $T_{\mathrm{c}}$ & $P_{\mathrm{r}}\left(\mu \mathrm{C} / \mathrm{cm}^{2}\right)$ & $E_{\mathrm{c}}(\mathrm{kV} / \mathrm{cm})$ \\
\hline 0.000 & 1420 & 5.29 & 508 & 0.55 & 0.019 & 1989 & 14445 & 371 & 11.9 \\
0.010 & 1320 & 5.48 & 283 & 0.37 & 0.016 & 2200 & 9196 & 365 & 2.89 & 2.62 \\
0.015 & 1280 & 5.61 & 208 & 0.31 & 0.027 & 2134 & 9366 & 363 & 1.48 & 2.82 \\
0.020 & 1230 & 5.58 & 382 & 0.47 & 0.026 & 2614 & 12112 & 360 & 5.28 & 1.55 \\
0.025 & 1210 & 5.20 & 167 & 0.28 & 0.013 & 3331 & 6333 & 346 & 1.27 & 2.19 \\
\hline
\end{tabular}

